White, I. (2013) "Firm Foundations or Castles on Sand? The Shifting Sources of Flood Risk and the Implications for Governance: an English Case Study", in Glavovic, B. and Smith, G. (eds) Adapting to Climate Change: Lessons from Natural Hazards Planning, pp 101-121, Springer. doi: $10.1007 / 978-94-017-8631-7 \quad 5$

\title{
Firm Foundations or CASTLES ON SAND? THE SHIFTING SOURCES OF FLOOD RISK AND THE IMPLICATIONS FOR FLOOD GOVERNANCE: AN ENGLISH CASE STUDY
}

Dr lain White

School of Environment and Development

Oxford Road, Manchester, M13 9PL. UK.

lain.white@manchester.ac.uk

\begin{abstract}
This chapter will provide an overview and analysis of the experiences of flooding in England since the end of the twentieth century with a view to informing debate in other countries. A critical reflection on the events of the last decade is particularly illuminating; encompassing a complete readjustment of our understanding of the sources of risk and subsequently exposing deficiencies in the ability of related governance frameworks to respond. The response to a series of damaging events from the scientific and policy making community was relatively swift, and included a significant change to the dominant paradigm from flood defence to flood risk management. This fundamental transition did, however, lead to a cascading series of interrelated governance implications and the development of new socio-technical assemblages, some of which were easier to anticipate than others. The effects encompassed alterations to the related methodology and a more neoliberal approach to risk management with repercussions for new responsibilities amongst a wider array of professions. The shift of the main source of flood risk from the rivers and sea towards surface water and drains was sudden and largely driven by forcing trends in climate and urbanization, creating the potential for lessons to be passed on to other countries who may experience similar pressures in the future; in essence to question the governance foundations shaping intervention - do they have longevity or, as was experienced in England, may they be castles on sand?
\end{abstract}

\section{KEYWORDS}

Riverine and coastal flooding; surface water flooding; risk management; governance; spatial planning. 


\section{INTRODUCTION}

If one thinks about flooding, what perceptions and images does it conjure? For most, if not all, it will be related to the sea or rivers being driven by powerful natural forces creating the potential to detrimentally impact on people and places. Similarly, if one considers how to manage flood risk, attention will logically focus on the provision of hard defences with a view to 'holding back' water. This chapter aims to confront these deeply ingrained perceptions by providing an insight into how a fuller understanding of the shifting sources of flooding in England has presented a fundamental challenge to understanding the risk, the most appropriate governance frameworks and the efficacy of the selected managerial responses; an experience that should provide valuable lessons for other countries subject to varying flood risks.

An accurate knowledge of the extent of the differing sources of risk is critical - not only may they demand completely different mitigation and adaptation measures, but, as this chapter will explain, they may operate outside of traditional scientific, financial and managerial frameworks, which have been mainly designed for structural responses. For example, defending the line against storm surges presents a very different proposition to addressing emerging threats generated from an excess of surface water in urban areas. Perhaps surprisingly, it is the latter that is now by far the biggest source of flood risk in England; a change that has only recently been recognised and its implications are still being considered within academia and practice. The effects of this shift in flood sources should not be underestimated - as it challenges hundreds of years of perception underpinned by supportive and interconnected governance paradigms, methodologies, professions and financial systems.

This chapter will firstly outline the logical reasons for developing the conventional approach to flood defence before analysing why it became subject to such rapid and sustained critique. It will then discuss the implications for governance that this shift in the sources of flood risk presented. Significantly, the potential forcing effects of climate change and urbanization on surface runoff means that the debate and inherent managerial difficulties experienced within the highly developed built environment in England since the turn of the $21^{\text {st }}$ century may provide valuable lessons for other cities and countries. As will be explained in the following section, there has been a tendency to first experience detriment before action occurs, but this reactive approach does not necessarily have to be replicated elsewhere. This does, however, entail critical reflection upon the limits to knowledge, engaging with uncertainty and re-examining systems of governance - all of which are currently in process within England.

\section{FIRM FOUNDATIONS OR CASTLES ON SAND?}


The United Kingdom (UK) is subject to both capricious seas and volatile weather patterns, which has contributed to the view that we have more 'weather' than most countries; with its sheer changeability leading to the well worn truism regarding it being a peculiarly British obsession. Like many aphorisms, there is more than a kernel of truth in this assertion and one unexpected benefit of this national fixation is a rich source of flooding records stretching back over 1000 years.

Within his $8^{\text {th }}$ century Ecclesiastical History of the English People the Venerable Bede, a monastic scholar, emphasised the geographical vulnerability of the country to the extremes of weather, detailing amongst other factors the effect of the seasons and the behaviour of rivers and the sea (White 2010). A further, more vivid example is provided by the Anglo Saxon Chronicle, which provides an important account of British history from the Middle Ages up to 1154 (Britannia 2007). Flooding events are recorded frequently throughout the document, with one of the notable events of 1014 described as:

This year, on the eve of St. Michael's day, came the great sea-flood, which spread wide over this land, and ran so far up as it never did before, overwhelming many towns, and an innumerable multitude of people.

In addition to coastal flooding, there is also a long record of flood events with regard to individual watercourses. The river Severn, one of the more notoriously flood prone watercourses in England, has been recorded as flooded 697 times since the first incident was noted in 1236 (Law et. al. 2010). The view that inundation is driven from watercourses and the sea is part of the national psyche in many countries beyond England, and, as we can see, there is usually good historical evidence why this should be the case. The reasons for the perception of flooding as being directly related to these sources are therefore understandable, having their roots in cultural history and harsh experience.

Considering this viewpoint, the approaches to managing flood water also developed logically, focused on increasing the defence against the undesirable intrusion of water onto land. A discrete and conveniently spatial risk, such as from these clearly definable sources, could therefore be effectively addressed via a strong wall alongside the sea or river. Similarly, an excess of precipitation in an urban area could be managed by an engineered drainage network designed to efficiently transport water to safe outfalls. In order to operationalise this approach, professions were gradually developed to specialise in better understanding the natural world, ascertaining probability to risks and implementing these engineering-led solutions. Over time, institutions and governance frameworks were also established to support flood defence, with responsibilities allocated to dedicated expert agencies. When considering the growth in knowledge, scientific expertise, finances and technology for much of the last century there is 
little doubt that great progress has been made in protecting people and property from the risk of flooding, and the success of this approach has helped it permeate across the globe.

Yet, given these advances one could be forgiven for assuming that flooding should be lessening, its risk increasingly understood and the threats better managed. This view is, however, far removed from reality. Although the science and technologies used to control water in England gained in sophistication, perhaps surprisingly the actual experience of flooding increased - and not just in isolated areas, but in a consistent manner across the globe. Whilst questions may be legitimately raised concerning population growth and the volume of people exposed, managerial strategies, particularly those in more technologically and scientifically advanced nations, should still be able to cope with long term, predictable social and land use trends. This is an important point to make, and provides the first initial challenge to our perception of both the causes of flooding and the subsequent efficacy of the managerial response. If societies are so adept at managing these events why do they keep experiencing severe and highly damaging floods? And why do they appear to be increasing in frequency?

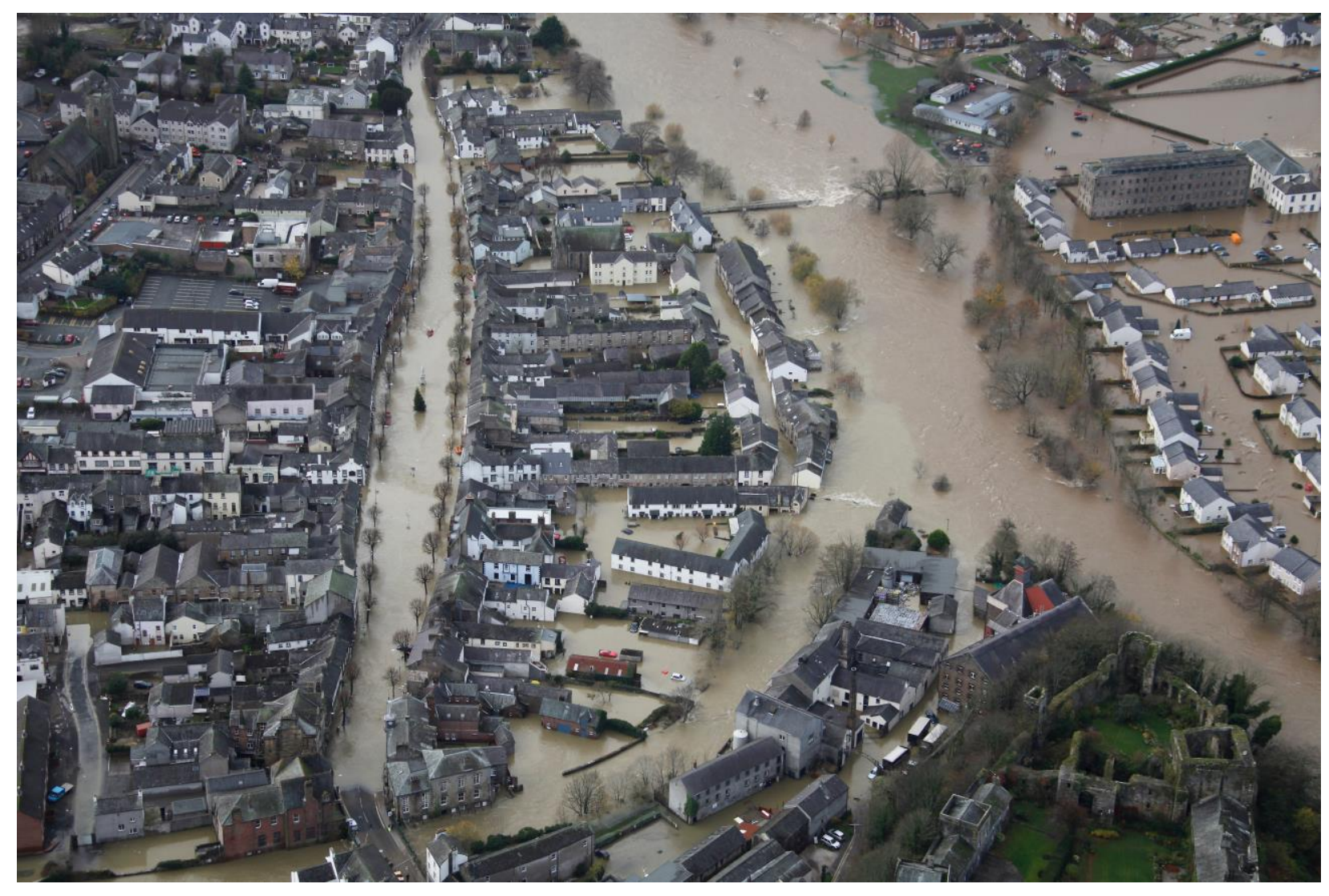

Figure 1: Aerial image of flooding in Cockermouth, UK during the November 2009 floods (C) Environment Agency/Peter Smith Photography). 
A common problem associated with policies to hold back water are that they may also increase risk via the 'escalator effect' (Parker 1995) or 'safe development paradox' (Burby 2006), whereby the provision of flood defences may make the land behind them appear more attractive for development. Allied to this is the driving role played by climate change and urbanization trends. However, given the progress in many fields over the $20^{\text {th }}$ century this chapter argues that it is also due to the highly imperfect understanding of the shifting nature of flood risk. In short, one of the reasons why flooding has continued to occur is that despite many perceptions it is not one homogeneous risk; a simple inundation of land may be the common result, but in practice there are an array of distinct sources, each subject to differing drivers and which are not analogous. In practice, flood risk comprises a number of spatially variable sources; from the well-understood threats emerging from rivers and the sea to emerging risks from urban runoff, infrastructure failure and rising ground water levels - each of which may demand differing adaptation strategies. The modern pluralistic nature of the threat challenged the long-held hegemony of perceptions, governance processes and appropriate intervention measures in England, and deserves equal consideration elsewhere.

\section{SHIFTING SOURCES: GLOBAL, NATIONAL AND CITY PERSPECTIVES}

Perhaps counter intuitively, given the rise in knowledge concerning flood defence, countries all over the world are becoming increasingly subject to flooding, making it one of the most frequent and widespread natural hazards. The second half of the twentieth century witnessed a rising number of flood events worldwide; a general trend being experienced on all continents, regardless of how advanced they may be (White 2010). If technology and science was so effective one would expect that these advantages would be reflected spatially, yet from a global perspective floods occur surprisingly well distributed. The uniform nature of the rise in flood events provides a challenge to how this hazard has been addressed, questioning the long-term efficacy of the dominant flood defence approach that has been applied on an international basis.

Although this information provides an argument for more effective intervention, there are a number of caveats. The first, concerns the theory of time-space compression (Harvey 1989) within which increasingly time appears to accelerate and space is compressed - or put more simply, technology may make it easier to quickly document events, regardless of where in the world they occur. From this perspective, contemporary societies may seemingly experience a rise in the recording of floods in comparison with less information-rich times. Secondly, there may also be disparities in defining what exactly constitutes a flood particularly when comparing records collated from differing spatial and temporal sources. Is it a simple inundation of water onto land? Do people and properties have to be affected? If so, how many would be required to turn a natural event into a disaster? 
Whilst we should problematise the argument for a long-term and global rising trend in flood events, there is greater confidence at the national scale. From an English perspective, recent data clearly shows an increasing number of damaging floods, particularly since 1998, thereby helping to counter the possible obfuscatory effects of space and time. These flood events resulted in three long established perceptions being confronted: the first concerning the actual sources of flood risk; the second relating to how floods have been governed and the closely related third, regarding the most effective intervention approaches to be adopted. During the transition from the late $20^{\text {th }}$ century to the early $21^{\text {st }}$ these long held views were initially gradually undermined, and then with a startling swiftness, almost completely reconstructed. And, crucially, it was driven by a repeated series of extremely damaging national-scale flood events - most notably in 1998, 2000, 2004 and 2007, supported by more localised, but very high profile incidents occurring in areas such as Boscastle, Carlisle and Cockermouth.

In the aftermath of each serious flood incident reports were commissioned which were not only helpful in determining the issues connected with a specific event, but from a recent historical perspective taken together provide an insight into the gradual changing awareness of the nature of risks and its rapid and significant impact on the policy narrative. Whilst each new flood event can prove devastating for the communities affected, it also presents an opportunity to cross reference existing information on risk and help provide additional data on ascertaining a truer picture of the sources of, and exposure to, inundation. The lessons of the last decade demonstrate how the agenda has quickly developed. For example, the report investigating the Easter 1998 flood exposed deficiencies in areas such as forecasting, warning, emergency response, standards of defense, severity assessment and management structures and skills (Bye and Horner 1998). Yet, it was the cumulative effect of the more widespread and severe Autumn 2000 flood suffered just two years later that Deputy Prime Minister John Prescott described as 'wake-up call'. Experiencing two huge events in quick succession that in some geographical areas the science estimated should only occur at least once in every 150 or 200 years inevitably casts doubt on the entire flood management process - particularly the methodologies associated with forecasting, prediction and exposure.

In the aftermath of the 2000 flood, measures were taken to improve these issues with, for example, a review determining that 1,724,225 properties were at risk of fluvial, tidal and coastal flooding (National Audit Office 2001). During this period there was no real acknowledgement of other sources of flood risk, which provides an interesting snapshot of just how far, and fast, flood risk management has progressed in a decade. A further step forward occurred a few years later with the publication of the Foresight Future Flooding report (Evans et. al. 2004). This wide ranging document provided the scientific evidence base to drive the emerging significant policy shift from flood defence towards flood risk management discussed in more depth later. Although at this time around two million homes were again identified as being at risk from flooding from rivers 
and the sea, climate change and urbanization were highlighted as powerful forcing drivers with exposure from surface water (incorporating urban runoff and local drainage failure) predicted to rise sharply from the highly uncertain level detailed in the report of around 80,000 properties.

The need not just for better information but more sharing of data on this source was also now becoming recognised amongst stakeholders. For example, figures on drainage were not held by the same agency as conventional sources of flooding and were not even within the public sector; the privatisation of the water industry in 1989 created ten separate companies each holding what may be commercially sensitive information. Although there was a suggestion in the Foresight report that the number of properties exposed to surface water flooding was almost certainly underestimated, it is doubtful that even the most pessimistic commentator would have predicted the extent to which this would prove the case.

In a related development, longer term and more sustainable water management methods began to influence the policy arena, underpinned by a move towards risk based approaches supported by scientific evidence. The ability to provide a consistently successful defence against flooding was now openly questioned, with a new pragmatism extolled and, despite the recent advances in knowledge and management, the message was that society should expect to experience periodic flooding, be prepared to 'live with water' and develop new working partnerships (White 2010). Notwithstanding this newfound realism, the rapidly developing scientific evidence base, supported by national, regional and local policy initiatives, led to a growing sense that although modern flood risk was more unpredictable and complex than in the past, society was again beginning to master some of the intricacies. For example, flood risk maps were now available online and as part of the planning process new developments may be subject to Flood Risk Assessments, incorporating consideration of modeling and downstream impacts (Department of Communities and Local Government 2006).

However, the wide scale summer 2007 flood inundated whole areas that were previously deemed to be 'safe'. This is a key point to pause upon. Whilst the transition from defence to risk management appears a logical response, how successful can a risk based approach be if it is so difficult to be accurate? And to what extent is the uncertainty inherent in this strategy understood and communicated to decision makers? This wasn't just a matter of a few degrees of probability, or a difference between a medium or high risk, but a failure to recognise whole swathes of the country as actually being exposed to flooding. As a result there was an increasing recognition that to date scientists and policy makers had concentrated on compiling information on the risk from coastal, estuarine or fluvial sources and there was a gap in knowledge concerning the extent of flooding from elsewhere, in particular from surface water and inadequate drainage (Pitt 2008). 
In part response, the most current data has again been revised upward to suggest that 5.2 million properties in England, or one in six of the total housing stock, are now at risk from flooding. With 3.8 million of those newly recognised as being exposed to inundation from the hitherto largely unrecognised source of an excess of surface water (Environment Agency 2009). Further, this exposure will continue to rise even if all unsafe construction stopped tomorrow, due to a gradual, incremental rise in urbanization elsewhere in the catchment and possible increases in rainfall intensity due to climate change. Indeed, it has been recently estimated as 'very likely' that global anthropogenic greenhouse gas emissions substantially increased the risk of the Autumn 2000 event occurring (Pall et al. 2011).

Despite only being newly formally included within calculations of national risk, flooding from surface water is now identified as the main source of flood risk in the country. Whilst changes in the definitions of 'risk' can vary slightly over time and between documents, Table One displays an accessible comparative overview of how quickly knowledge has changed regarding both the estimated number of people at risk and from which source, encapsulating data from advances in ascertaining exposure and the reviews of recent flood events. The table is designed to be useful as a didactic device; not necessarily with regard to attaching significance to the number of properties, but rather as a demonstration of the way that seemingly firm foundations can quickly be undermined and how academics and policy makers in countries outside England should learn from this experience and question what may ostensibly appear to be very certain scientific datasets.

Table One: The changing knowledge of the sources of flood risk exposure in England since 2000 (National Audit Office 2001; Evans et al. 2004; Environment Agency 2009).

\begin{tabular}{|c|c|c|c|}
\hline \multirow{2}{*}{ Year } & \multicolumn{2}{|c|}{ Estimated properties at risk by source } & \multirow{2}{*}{ Total } \\
\hline & Rivers and Sea & Surface Water & \\
\hline 2000 & $1,724,225$ & 0 & $1,724,225$ \\
\hline 2004 & $1,740,000$ & 80,000 & $1,820,000$ \\
\hline 2009 & $2,400,000$ & $3,800,000$ & $5,200,000^{1}$ \\
\hline
\end{tabular}

${ }^{1}$ Note that 1 million properties are at risk from both sources of flooding (Environment Agency 2009). 
Within the space of nine years the overall estimated exposure to flood risk in England has more than tripled, with surface water and drainage emerging from being completely unacknowledged to accounting for two thirds of the total risk. Whilst reflecting on the rapidly changing data compiled during this time, the speed of development does inevitably expose flaws in both the evidence base and governance of flooding. However, the relatively quick response of the scientific and policy making community to identify, and adjust to, new and emerging risks should also be recognised. The shifting sands of what were thought to be relatively firm foundations in such a short space of time exposed, perhaps understandable deficiencies in fundamental aspects of flood risk management; knowledge gaps that had inhibited the ability to respond to all sources of flood risk. The financial and governance focus on structural defences merely addressed one part of the picture, and it was only after the inadequacies in this approach were revealed that changes were initiated. The events therefore provided the evidence and the momentum for what will be argued was a fundamental shift to how flood water was both perceived and managed. It may be that the experiences of policy makers in England, whereby damaging events demanded reviews, which in turn led to wide-ranging recommendations and responses, can provide salutary lessons to differing countries subject to similar climatological and societal drivers, particularly where there is a heavy focus on pursuing 'defend the line' approaches.

Reducing further in scale to the city level, data from the ten local authorities that make up the Greater Manchester city region provides a similar reinforcing story of changing flood sources; albeit a more gradual and incremental shift in contrast with the succession of sharp shocks from the national perspective. The inland area is accustomed to managing a relatively high rainfall and has experienced floods from both riverine and surface water sources, yet analysis of the events and their causes provides supporting evidence of a localised shift in risk that reflects the national trend, with similar managerial and adaptation implications.

Figure 2 outlines the differing frequency of these two flood types between two periods: from 1945 to 1997; and from the first of the recent major national floods in 1998 until 2009. Overall, flooding from watercourses has steadily decreased, which has been more than offset by a rapid increase in surface water events, with the average up from 0.38 to 3.10 events per annum. Whilst the localised nature of these floods may not be as devastating as those on a national scale, their similar rising frequency and changing composition provides evidence of both the shift towards surface water flooding and the difficulties within the governance systems to both recognise, and adjust to, inundation from this source. On reflection it could be argued that there is some truth in the perception introduced at the start of the chapter that societies are getting better at managing floods - but as these figures suggest, just from what could be termed 'traditional' sources. The investment in river and sea defence has brought benefits, but while the focus has been centered here not only has the risk shifted elsewhere but it has grown in strength. The overall number of floods discussed at the start of the chapter does suggest that there have been 
governance inadequacies, but this view is reinforced when analysing how governance frameworks have addressed the possible sources of inundation, where there has been a clear emphasis on floodplain protection via structural defences.

Riverine

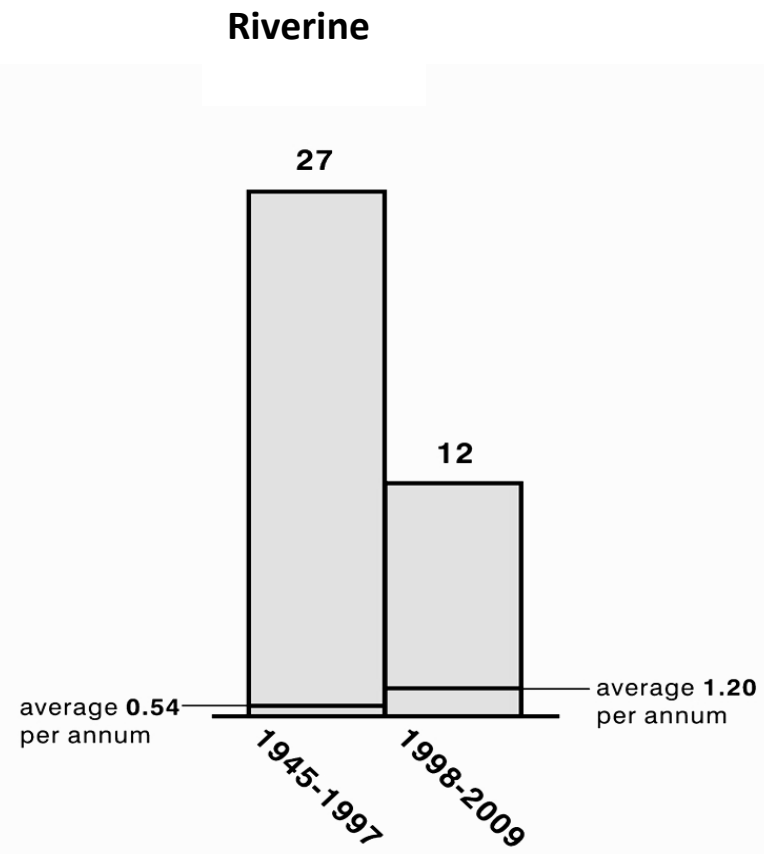

Surface Water

31

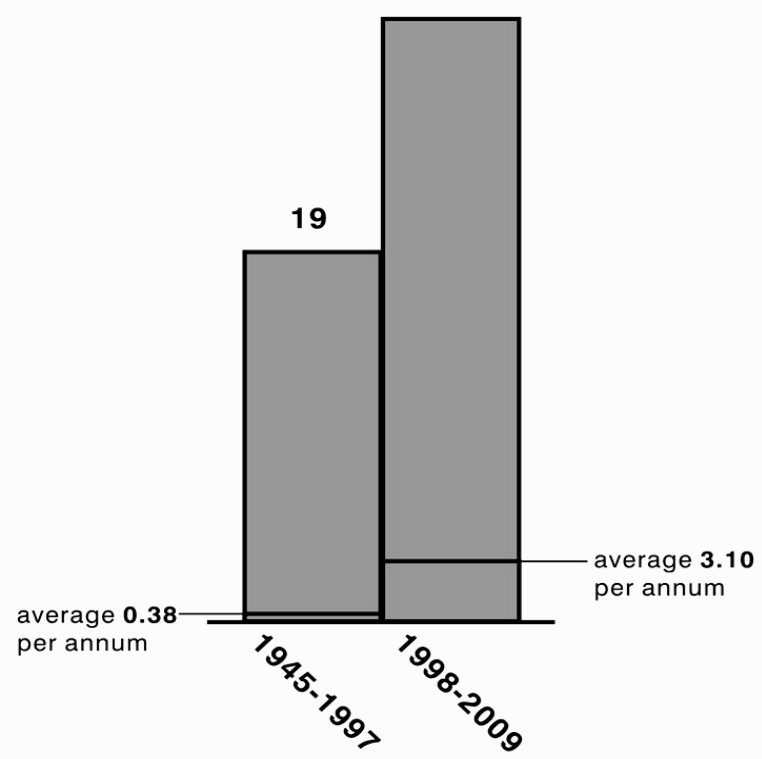

Figure 2: Riverine and surface water flood events in Greater Manchester (Lawson and Carter 2009).

At its simplest level, the lack of success in preventing flood events, regardless of their scale, could be considered a series of governance failures - with an array of culpable stakeholders identified by the press and public from the government to planners to the Environment Agency. Yet, in the absence of experiencing serious and widespread flood events, and with no real international lessons to draw upon, one could be forgiven for assuming that the threat of inundation was both driven by rivers and the sea and under relative control. In reality, the evidence argues for a more pluralist approach; one that extends the view of flooding beyond the geographical floodplain and therefore challenges the traditional hegemony of existing governance frameworks that are overwhelmingly designed to deliver structural defences. As the chapter will also show, this shift is a work in progress and not only may there be an implementation gap between what a policy advocates and its translation into practice, but also a 'governance deficit' with surface water in particular being subject to a complex framework of responsibilities (Douglas et al. 2010).

\section{Cascading Governance Implications: paradigms, methodologies and} RESPONSIBILITIES 
The changing sources of flooding and the resulting paradigm shift from defence to risk management have had significant effects on fundamental issues such as the desired managerial approach and the actors and agencies charged with determining intervention - some of which have been easier to foresee than others. The operationalisation initially required a change in methodological emphasis from the probability based technique developed throughout the twentieth century to a risk management approach focused on a broader scientific understanding. This in turn required a challenge to the professions, moving flooding beyond the realm of engineering towards other experts, most notably spatial planning. The changes in governance also had an effect on who is responsible for managing flood risk, with power and also accountability devolved away from the State and towards a wider array of stakeholders, including communities and individuals.

In just over a decade managing flooding in England has moved to being within the remit of almost everyone, from government ministers to local authority planners to homeowners. Considering the inertia and conservatism inherent in many of the areas of governance affected the response has been brisk, but the sheer scope of areas that required attention was undeniably challenging. Figure 3 summarizes the key governance implications which have been gradually revealed and implemented by the recent failure to protect people and places against flooding - a cascading series of managerial shifts that occurred once the move from flood defence to flood risk management was operationalised at the start of the $21^{\text {st }}$ century. The information contained in the figure is not designed to delineate an absolute transfer of power or a dialectic between the technical and social, it is more about revealing new hybrids of knowledge, or even more simply, a direction of travel. This shift has provided the foundation of a more effective management of flooding and will be of relevance beyond the English case study.

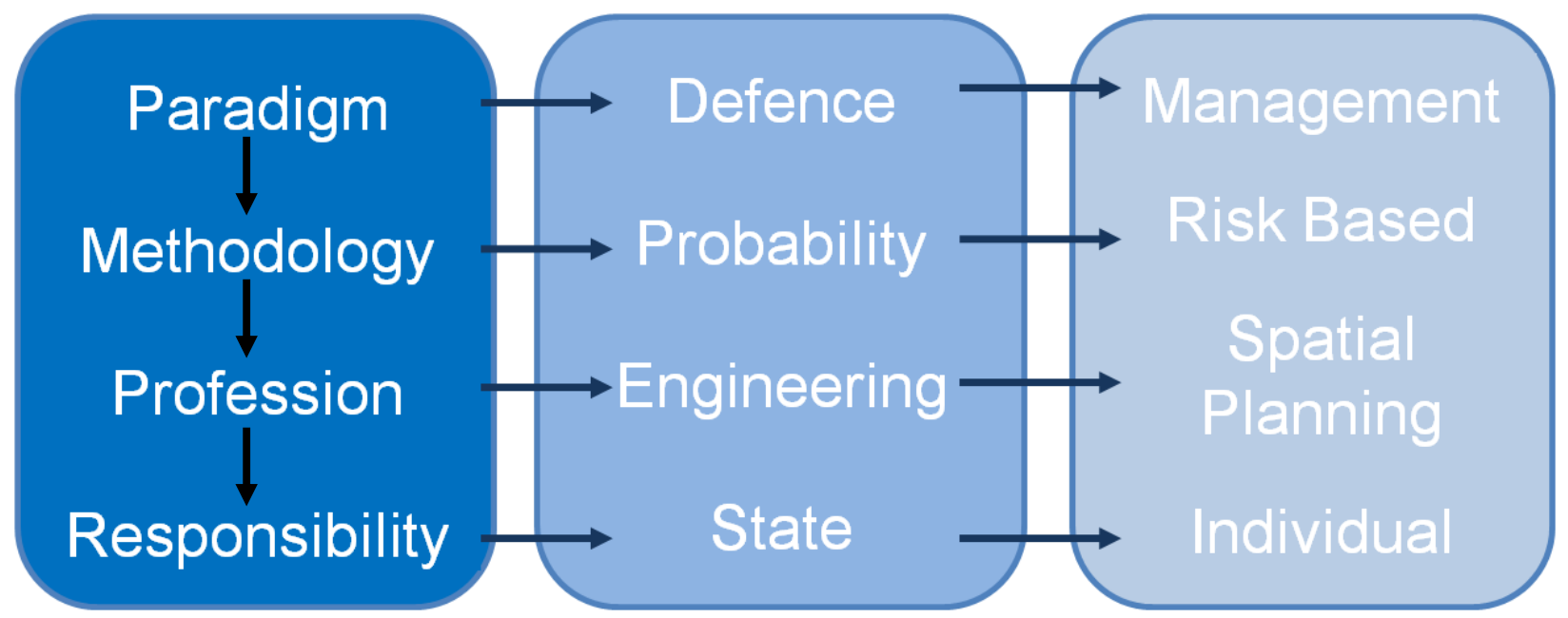

Figure 3: The interconnected cascade of recent and emerging shifts in the governance of flooding. 
Each key aspect is discussed in more depth in the following sections which detail the interrelated cascading response to the realisation that the governance foundations designed to address flood risk were not as secure as previously thought. This involves analysis of the changing flood management paradigm, the methodology employed, a widening of the professions connected and a devolution in stakeholder responsibilities.

\section{PARADIGM CHANGES}

The succession of flood events combined with an awareness of the difficulties in managing water led to an acknowledgement within government that it was unrealistic to assume that all floods could be prevented. The long established 'flood defence' paradigm could not be effectively applied to the highly uncertain events of the $21^{\text {st }}$ century, and there was a distinct shift towards 'flood risk management' - an alternative, more comprehensive approach that aims to avoid new risk where possible and includes wider human and socio-economic factors. Moreover, recognizing that the problem was not just one of controlling water - as risk could also be beneficially influenced by managing people - effectively widened the stakeholders involved and the scope of policy influences with links to flooding. Whilst hard engineering and restrictions on floodplain development would continue to be important, non-structural measures began to be seriously discussed - ranging from green infrastructure to planning policies to insurance provision. The move towards pluralism also meant that the blame for any future floods would be both harder to assign and more widely distributed; within a defence paradigm arguably any flooding is a failure and the people responsible for implementing this approach culpable; within risk management some flooding could be expected and multiple stakeholders bear a share of the responsibility if any is assigned.

A significant development driving this change was the gradual acknowledgement that flood risk, such as expressed in Table One, occurred from sources beyond rivers and the sea. It should be recognised that this threat still exists, and that structural defences are very effective mechanisms to address this source, but that the spatial and managerial certainty inherent in such an approach could not be easily transferred to the problem of surface water flooding. Essentially, the hard surfaces of a city perform as a multiplicity of artificial water pathways, operating in a complex and seemingly chaotic manner. The urban streets can therefore be considered as a part of the drainage infrastructure, and like any system can fail under high pressure.

The difficulties presented to the flood defence approach connect to the ability to accurately predict the interaction between precipitation and the urban environment: where will the water pond or flow? What size of event will trigger dangerous levels of runoff? Which spatially discrete location will be exposed and how will climate change and urbanization affect this? But all these questions should be considered in the context of the dominant managerial paradigm of the time - if both the volume of runoff and the areas that generate and receive it are unpredictable, 
irregular and multiplex how do you respond via structural measures? Or in short, how can a society adopt a'defend the line'approach when a line can't be identified?

The shift towards flood risk management could better address the twin issues of urban runoff and the rise in uncertainty however; where floods cannot be reasonably prevented their effects can be prepared for and the impacts lessened. To operationalise the new paradigm therefore required a further reassessment of the methodology determining where and how we should intervene: flood defence is tightly connected to an engineered response supported by probabilistic calculations; flood risk management is more diffuse and combines wider nonstructural approaches. To be effective required a significant re-examination of the methodology employed by the scientific and policy making communities in England to inform intervention.

\section{Methodological CHALlENGES ASSOCIATED WITH FLOOD RISK ASSESSMENT}

The way we interpret risk shapes responses. From a flooding perspective, it is the recent paradigm challenging awareness that the majority of flood risk in some cities may not come from the readily identifiable and geographically fixed floodplains and coasts that presents the strongest argument for a new approach. For example, as outlined in Table One, in 2004 in England there were an estimated 80,000 homes at risk from surface water flooding, a figure that rose to $3.8 \mathrm{~m}$ in the space of five years. It is helpful to reflect on the implications that this fundamental shift may have had on those concerned with flood defence. How can flooding be managed when traditional hard defence engineered approaches may not only be irrelevant to this risk, but there may potentially be hundreds of separate sources of flood risk which defy quantification? Moreover, how can probability realistically be considered as a basis for decision making in this situation?

The first lesson to take from the English experience is regarding the concept of certainty. It is dangerous to assume that knowledge is established and that the threat of flooding operates in a definable and predictable milieu. Ascertaining the extent of flood risk necessarily demands an engagement with uncertainty; in reality we use unreliable and imperfect knowledge to provide a basis for action in how we use and manage land. Moreover, although the calculations may appear precise this is a highly transient position; in practice they are temporally static yet may be expected to be applied within a highly dynamic environment and be accurate many years into the future. We know climate change and urbanization will exert a significant, yet elusive, forcing effect on risk, but how effective will decisions be in five, ten or twenty years time? This quandary may be understood as challenging the principle of stationarity, a central tenet around which the analysis of hydrological time series is founded. Whilst it may be expected that precipitation varies daily, seasonally and annually, over a longer time series it has been assumed to be stationary that is one record should be comparable to another (Zevenbergen et al. 2010). This data has informed flood defence and drainage strategies, has underpinned decision making and links well 
with a probabilistic engineered-led approach. Yet surface water flooding transferred the threat of inundation to the urban environment, a changeable and expanding place that alters over time and space, sometimes significantly. Further, when you also consider the unpredictability of climate change, it is clear that applying a static, conservative methodology to what may be a highly dynamic environment can underestimate the threat due to a failure to incorporate forcing drivers altering the properties of a system.

Whilst information on recurrence intervals can be of use in providing a retrospective indication of the relative strength of an event in comparison to past floods, its veneer of scientific certainty regarding future risk should be viewed as illusory. In reality, the urban system is subject to such significant variability that its value in aiding strategic decision making is actually of limited value. Indeed, a recognition of this statistical uncertainty has helped drive the shift from probability based approaches towards risk and resilience, as has happened in many countries in incremental stages over the last decade.

The second issue to note is related to the concept of certainty and is regarding the subsequent desire for quantification. The development of flood management as being within the remit of experts, and in particular within the auspices of professions such as engineering and scientific modeling, created an understandable desire for confidence and surety closely associated with these fields. Quantification is not a natural bed fellow of complexity however; and as the uncertainty associated with flood risk management rose, so errors with this approach were exposed. In practice, the precise volume and location of urban land at risk from flooding may be highly tentative, raising questions as to the extent to which uncertainty regarding the existence or strength of a hazard may be reduced to a calculation of probability (Hanssen 2009). Therefore a methodology centered on ascribing a figure to communicate a notional risk and inform decision making may have flaws both externally, by creating spatial inequalities based on the availability of appropriate data, or internally, by only considering certain aspects of the risk, such as those which are most easily quantifiable.

The simplistic language of risk calculation may falsely reduce uncertainty to a comforting illusion of deterministic, probabilistic processes within which the inherent gravitas of scientific calculations can attach a misleading confidence to what may be very cautious outcomes. This was a point recognised by Wynne (2009: 308) who argued that this methodology for managing risk is erroneous and: 'the dominant risk science approach is more than a method; it is a misbegotten culture which inadvertently but actively conceals that ignorance'. Whilst understanding hazard management in this manner can be useful as a simple communication tool it is helpful to move away from a dominant view that risk can be definitively measured; it can't. In reality, attaching a probabilistic value to a highly uncertain event may actually be an extremely 
tentative judgement masquerading as hard scientific truth; as Adams (1995: 29) puts it: 'risk is constantly in motion'.

The acknowledgment that the management of natural hazards is connected to our perceptions and constrained by information in turn forms the basis of the more contemporary standpoint that responses are socially and culturally constructed. Beck (1992: 99) argues that the perception of risk has become shaped by the desire for quantification and the expansion of the insurance industry and referred to:

...systematically caused, statistically describable and, in this sense, 'predictable' types of events, which can therefore also be subjected to supra-individual and political rules of recognition, compensation and avoidance.

However, it was these 'rules of recognition, compensation and avoidance' that helped drive the shift away from a narrow, reductionist probabilistic methodology, as the impacts of the floods damaged the very political, scientific and financial sectors that underpinned the approach. The legitimate questions, as to the extent to which uncertainty regarding the existence or strength of a hazard may be distilled to a calculation of probability, drove the move towards more holistic risk management, where probability was offset by a more precautionary approach and a wider array of social, economic and environmental factors were considered. Achieving this shift required a much broader engagement with flooding than ever before, within which the management of water now includes professions beyond the traditional spheres, such as engineering and modeling, to incorporate all those with influence over support systems and particularly those connected with where people live and how they act.

\section{WIDENING PROFESSIONS}

As the previous sections argue, one of the reasons why the effective management of floods has been placed under pressure is that their causes have been influenced by the dynamic and uncertain processes of urbanization and changing weather patterns. Yet, it is too simple to suggest that these influences should equal more damaging events as there has been a huge increase in investment in flood risk management over recent years. According to the Department for Environment, Food and Rural Affairs (Defra) (2010) the flood defence budget has risen sharply since the first of the major national floods in Easter 1998, with an estimated $£ 765$ million forecast in the $2010 / 11$ financial year, in comparison with $£ 310$ million in $1997 / 98$ and $£ 590$ million in $2007 / 08$. This also partly explains why flooding from the rivers and the sea has arguably become better managed, as this spending was mainly focused upon new capital projects, and to a lesser, although annually rising extent, on the maintenance of existing structural defences.

This may also help clarify why technologically, financially and scientifically well resourced nations, such as those within Europe and North America in particular, are experiencing a similar rising 
frequency of floods as countries elsewhere, as human activity - from the burning of fossils fuels to urban development - can help to create new risks or shift existing ones. The move in the sources of risk towards threats from surface water, closely related to a highly developed built environment, did provide a specific funding problem however, as the agencies with power over flood defence spending were not configured to positively influence the flow of water in urban or rural areas, which would mainly rest with the local water and sewerage provider, the agricultural sector and local authorities. The need to address the issue of stationarity also ensured that those professions with influence over future risks, from controlling new development to increasing the ability to store water within the catchment more generically, also became important actors in flood risk management; with spatial planners now firmly at the forefront.

Although it was the Easter 1998 floods that proved the catalyst for the first planning policy guidance on flooding released a few years later (Department of the Environment, Transport and the Regions 2001) the role of planning in managing this risk was still in its infancy and in comparison to the established professions it was very much the junior partner. Over the decade its role steadily grew however, as its contribution became more widely accepted and planners more adept at exerting influence in this unfamiliar sphere (White and Howe 2002; White and Richards 2007). The new emphasis for the planning profession was also reinforced in related scientific research (Evans et al. 2004) and policy documents, with, for example, Defra (2004: 7) stating:

The Government is committed to ensuring that its development and planning policy seeks where possible to reduce, and certainly not to add to, the overall level of flood risk.

The growing threat of surface water flooding continues to bring a real critical mass to this shift however, and is essentially helping to widen responsibility from the engineering-led professions towards those concerned with people and places, and in particular those with influence over the interaction between the built and natural environments. Spatial planning is now accepted as one of the key mechanisms to avoid, reduce and manage flood risks (Communities and Local Government 2010) and operationalise the paradigm shift initiated in the early $21^{\text {st }}$ century. Structural and non-structural options are now routinely considered as viable measures in both reducing risks and adapting in the future, although the differing actors and agencies involved increase the potential for more effective strategies. They also instill a greater complexity of policy choices and the need to construct negotiated policy agreements across this growing network of stakeholders.

The role of the professions is not just an external relationship, where the involvement of more skills and knowledge should lead to better decisions, but also an internal dialogue - wherein discourse within and between people and organisations in key sectors takes place. Enacting such a shift in governance from the technical towards more complex socio-technical assemblages 
inevitably takes time to become effective in practice, particularly where the risk is subject to uncertain spatial and temporal influences. To operationalise the new paradigm therefore requires changes to how professionals understand, and act upon, flood risk across a broad range of areas, and potentially within sectors without the long history of flood management as detailed in the first part of the chapter. As the next section will emphasise however, not only do multiple agencies communicate more effectively, but this approach also means that responsibility now goes way beyond the formal professions towards the citizen and their relationship with both the state and the market.

\section{DEVOLVED STAKEHOLDER RESPONSIBILITIES}

One significant implication of the move from flood defence to flood risk management was that the simple chain of responsibility between the State and its key managerial organization in this area, the Environment Agency, was unraveled. The 'living with risk' agenda, within which prevention is advocated alongside an ability to cope with any possible impacts, could be pursued across multiple scales and professions; including the public sector, the private sector, communities, households or even individuals. As problems could be exacerbated by forces beyond the control of any one agency there was also an onus on shared responsibilities. Although the newer strategy adopts a similarly spatial approach as previously, the re-examination of scale better reflects the realities of the risk and, significantly, artificial administrative boundaries became challenged as inappropriate with new plans advocated at the city, catchment or regional scales. Whilst recognising the wider variety of professions with the ability to influence flood risk and providing a broader array of mechanisms to influence policy options and outcomes was a clear step forward, there is still an ongoing need to work together better, as actions in one part of the catchment can have a significant affect elsewhere. A good example of this is detailed in Figure 4 where the Greater Manchester region in North West England has been broken into its ten local authorities to better demonstrate the interconnected hydrology. Each area details both the future housing targets to 2021 and the direction of water flow between the most significant rivers and canals. 


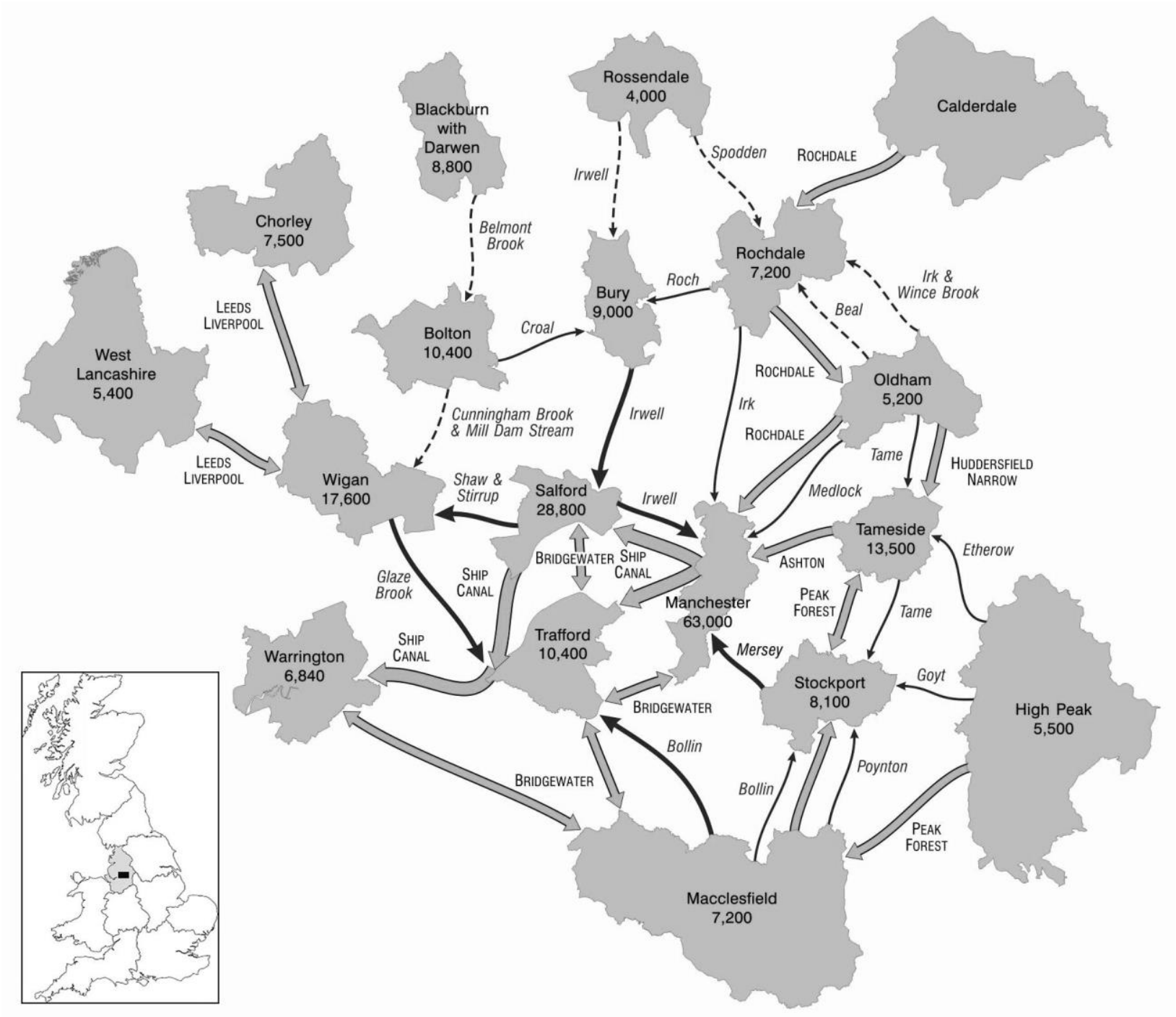

Figure 4: Housing allocations and hydrological links schematic of Greater Manchester in the North West UK (adapted from Scott Wilson and AGMA 2008).

The figure provides an understanding of the shape of the catchment, with water from the higher surrounding areas flowing towards the western side of the conurbation. The diagram outlines how the outer authorities essentially export their runoff into Salford, Trafford and the outlying area of Warrington, emphasising the cumulative nature of risk and the need for flood risk management to be a collective responsibility. Indeed, if all the housing targets are met, a total of 145,100 new homes, and their associated infrastructure, will be constructed upstream of Salford by 2021, an area already at relatively high risk of flooding. The externally driven hazard argues for inclusive partnerships and spatial policies that are coherent with the priorities of neighbouring authorities.

The new roles also extend beyond the public sector and related professions. The rise in information enabled the State to devolve responsibility away from the centre, with both the 
private sector encouraged to play a part, such as via insurance and flood resilience products, and communities and people expected to consider how to reduce their own exposure and vulnerability. Facilitating the shift required information on flood risk to be collected and made publicly available, with, for example, people encouraged to consider their own acceptable level of risk by checking online maps provided on the Environment Agency's website when purchasing a house (Figure 5). However, as with other risk management techniques these tools may not effectively communicate the certainty of calculations, utilise unfamiliar nomenclature and focus on spatially representing the more easily quantifiable risks from rivers and the sea (Merz et al. 2007).

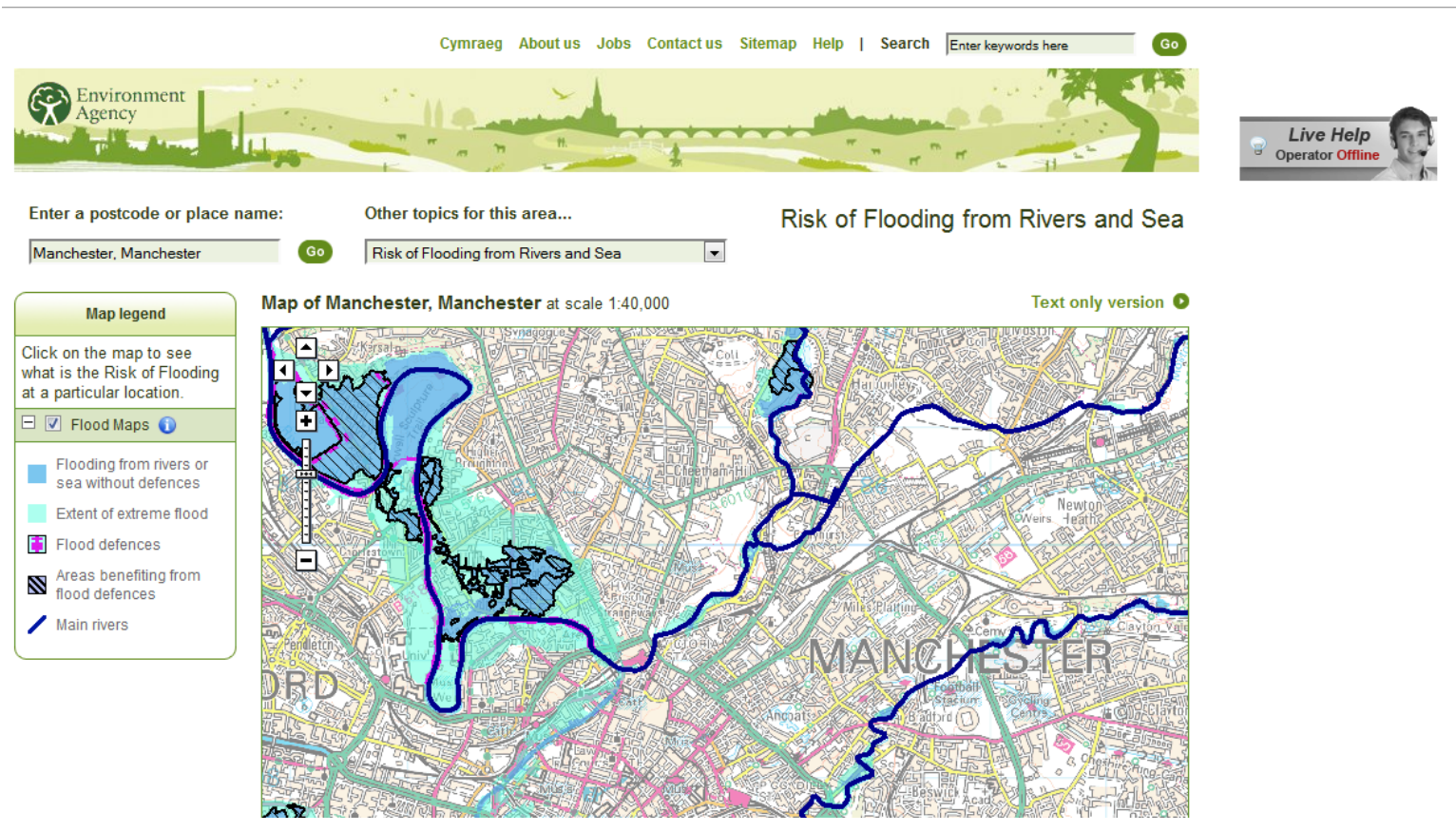

Figure 5: A screenshot of the Environment Agency's Flood Map service, which encourages individuals and communities to become more aware of flood risk (Contains Environment Agency information (C) Environment Agency and database right. 2012).

The wider implications of the trend to devolve power and responsibility away from the State towards communities and individuals are still emerging. Risk management, like 'sustainability' or 'progress', is one of those agreeable, pliable and nebulous concepts that it is difficult to argue against. Although a contrary position may appear to be counter-intuitive, the lack of contention does not mean that the concept should be uncritically unpacked, automatically promoted or unthinkingly applied. Far from being a universal good, when this approach is translated into practice there may be significant spatial inequalities within society, many of which may be unwitting externalities. Once individuals and communities are encouraged to take responsibility for the level of risk they wish to be exposed to, and protection from flooding commoditised via the public sector, there will inevitably be winners and losers. There are also wider questions 
about the long term social justice implications, of both the initial paradigm shift and its resultant effects. The move to flood risk management was a pragmatic policy decision reflecting the unpredictability of a flood defence approach, but would communities actually want to live with water or do they just want the state to keep them safe? The implications of this final shift in the governance chain are only just being considered within academia and policy and, reflecting on recent history, there is a possibility it may require another serious flood event to shed light on the social impacts of devolving responsibility from the State towards the private sector, communities and individuals.

\section{Discussion AND CONCLUSION}

This critical analysis of both the shifting sources of flood risk and the governance implications of a change in approach reveal a cascading series of impacts. Some of these were anticipated and have been already experienced, others were difficult to recognise and are still being unpacked. Although flood defence decisions were made using the best available information within a long established scientific approach, this techno-rational process of considering hazards in this narrow probabilistic manner and using it as a basis for judgement not only fails to adequately address the differing sources of flooding, but effectively helps to immunize decision making from failure (Reith 2009). A reductionist probabilistic approach can provide a comforting veneer of efficacy and certainty but it may be a deceptive state where flaws can continue until the strength of detriment demands the need for a re-evaluation of the entire methodology. That is not to say that modeling is not useful, particularly at a large catchment scale, but it should be reinforced by broader knowledges and new understandings of local level risk management. In hindsight, the focus for intervention has been quantitative and based squarely on what is known; when in reality more attention could have been profitably spent on a precautionary approach cognisant of what is unknown.

The shift in risk from rivers and the sea towards surface water will be one of the emerging challenges on the early twenty first century in many developed areas, particularly when considered in conjunction with the rise of more extreme climatic events and burgeoning urbanization. Flooding is subject to differing geographies, where, for example, the behavior of a coastal floodplain is eminently more predictable and manageable than intra-urban flooding, which is a landscape subjected to a wide array of drivers and affected by the powerful binary influences of the natural and built environments. Both risks are relevant to a modern flood risk management approach however, and this chapter doesn't aim to provide a discussion of the dialectics of defence versus risk management, more a tempering of the former and recognition of its inherent governance constraints as a tool to address surface water.

The hydraulics beyond the boundaries of the sea or watercourses are subject to the multiplex forces of urbanity, where water flows in unpredictable ways and can be constrained or released 
according to what may be indeterminate pinch-points. One logical way of reacting to this rise in uncertainty inherent in threats from surface water is to make our cities more aware of, and resilient to, flood risks - and in this respect proactively and strategically influencing the current and future use of land is key. Therefore, it may be that the most significant shift in the management of water in England and beyond will not be the one from flood defence to flood risk management or from probability to risk based approaches, but rather the emerging transition in power and responsibility from engineering to spatial planning and from the State to the individual. Whilst there will always be a role for providing hard structures to defend against flooding, there will clearly be a stronger responsibility to link water concerns with where, and how, people live. The implementation of new, more appropriate policy initiatives, such as the European Flood Directive (European Commission 2007), may potentially provide the basis of firmer governance foundations but their implementation still needs to influence a complex managerial arena.

Each disaster drives a spectrum of possible action from reflection to revolution; improvements which may not be achievable without first experiencing these potentially catastrophic drivers. Yet the extent and consequences of flood risk argue against such a reactive approach; should we only change in direct response to disasters, or should we use scientific knowledge to help predict and adapt? Whilst it is acknowledged that damaging events do have the potential to set the agenda (Kingdon 1984) or create momentum for policy change (Johnson et al. 2005), this is an unsustainable, reactive process within which changes occur after experiencing detriment. Within risk and disaster management, all too often suffering damaging events is a key phase as they stimulate reflection and reaction, but this doesn't have to be experienced in each country individually and it is here that this chapter may provide key lessons. From a period of relative stability England became quickly subject to frequent damaging floods to the extent that the collective awareness is moving from a feeling of safety toward the more realistic viewpoint of 'before the next catastrophe' (Perrow 2007), galvanising action to protect people and places and challenging managerial norms.

It may well be that just as the flood defence approach spread across the globe during the last two centuries, the direction of travel from defence to management, from probability to risk, from engineering to spatial planning, and from the State towards the individual, will resonate with many different cities and countries. Therefore the strategies adopted in England, unfortunately at the forefront of surface water risks, and the resulting series of governance changes gradually developed to operationalise the shift in approach, may help others break the closed cycle between detriment and policy change. The new hybrids of knowledge and understanding being developed represent a logical response, but it should be noted that these changes were not all implemented as part of a comprehensive strategic redirection, but have rather grown organically as the implications of the initial paradigm shift adopted to manage this hazard became apparent 
in practice. Other areas could use this international comparison to plan intervention more strategically however - the perception of flooding as one homogenized risk emerging from rivers and the sea has created governance frameworks which may not be well suited for responses beyond this conveniently quantifiable and spatial area.

Whilst the move towards flood risk management greatly enhances the ability to both protect people and lessen any impacts, far from being a universal good, in reality when such a managerial shift occurs there are often significant governance challenges or spatial and social inequalities, many of which have only been revealed through experience. In reality, what may appear to be a simple, benign and progressive paradigm change has actually transpired to be a cascading series of powerful governance changes, the implications of which are still being analysed. Moreover, these transformations may require new socio-technical assemblages developed to manage the interaction between flood governance and human behaviour. Adaptation to climate change is not a predictable, neutral, value free process; natural hazards can challenge long held conventions and adjusting intervention measures can bring new and often difficult to anticipate problems. In hindsight, the governance of flooding in England has been revealed to be on less firm foundations than envisaged, yet the heuristic and sometimes harsh experience in addressing natural hazards has the potential to provide valuable lessons for elsewhere.

\section{ACKNOWLEDGEMENTS}

Thanks to Professor Graham Haughton, Dr Yasminah Beebeejaun and Dr Angela Connelly of the University of Manchester for their comments. I also would like to extend my gratitude to the Environment Agency for allowing the reproduction of their images.

\section{BIBLIOGRAPHY}

Adams, J. (1995) Risk, London: University College London Press.

Beck, U. (1992) Risk Society - towards a new modernity, London: Sage.

Britannia (2007) Anglo Saxon Chronicles. Online. Available HTTP: <http://www.britannia.com/history/docs/1014-17.html> (accessed 12 October 2009).

Burby, R. J. (2006) Hurricane Katrina and the Paradoxes of Government Disaster Policy: Bringing About Wise Governmental Decisions for Hazardous Areas. The Annals of the American Academy of Political and Social Science, 604 (1): 171-191.

Bye, P. and Horner, M. (1998) Easter 1998 Floods: Volume 1. Report by the Independent Review Team to the Board of the Environment Agency. Environment Agency: Bristol.

Communities and Local Government (2010) Planning Policy Statement 25: Development and Flood Risk, March, London: The Stationery Office. 
Defra (2004) Making Space for Water: Developing a New Government Strategy for Flood and Coastal Erosion Risk Management in England, London: Defra.

Defra (2010) Flooding - Investment Allocation. Available HTTP: $<$ http://www.defra.gov.uk/environment/flooding/funding/allocation.htm $>$ (accessed 29th November 2010).

Department of Communities and Local Government (2006) Planning Policy Statement 25: Development and Flood Risk, December, London: Department of Communities and Local Government.

Department of the Environment, Transport and the Regions (2001)Planning Policy Guidance 25: Development and Flood Risk, London: HMSO.

Douglas, I., Garvin, S., Lawson, N., Richards, J., Tippett, J. and White, I. (2010) Urban pluvial flooding: a qualitative case study of cause, effect and non structural mitigation, Journal of Flood Risk Management, 3, 112 - 125

Environment Agency (2009) Flooding in England: A National Assessment Of Flood Risk, Bristol: Environment Agency.

European Commission (2007) Directive 2007/60/EC of the European Parliament and of the Council of 23 October 2007 on the assessment and management of flood risks. Available at $<$ http://ec.europa.eu/environment/water/flood risk/index.htm $><$ accessed $8^{\text {th }}$ February 2011>.

Evans, E., Ashley, R., Hall, J., Penning-Rowsell, E., Saul, A., Sayers, P., Thorne, C. and Watkinson, A. (2004) Foresight: Future Flooding. Scientific Summary: Volume 1, Future Risks and their Drivers, London: Office of Science and Technology.

Hansson, S.O. (2009) 'A Philosophical Perspective on Risk', in Lofstedt, R.E. and Boholm, A. (eds) The Earthscan Reader on Risk, London: Earthscan.

Harvey, D. (1989) The Condition of Postmodernity: An Enquiry into the Origins of Cultural Change, Cambridge, MA: Blackwell.

Johnson, C. L., Tunstall S. M. and Penning-Rowsell, E. C. (2005) 'Floods as catalysts for policy change: historical lessons from England and Wales', International Journal of Water Resources Development, 21, (4), 561-575.

Kingdon, J. (1984) Agendas, alternatives and public policies, Harper Collins: New York.

Law, F. M., Black, A. R., Scarrott, R. M. J., Miller, J. B. and Bayliss, A. C. (2010) Chronology of British Hydrological

Event.Available HTTP:<http://www.dundee.ac.uk/geography/cbhe/\#searching $><$ accessed $29^{\text {th }}$ November 2010>. 
Lawson, N. and Carter, J. (2009) Greater Manchester Local Climate Impacts Profile (GMLCIP) and assessing Manchester City Council's vulnerability to current and future weather and climate, Ecocities Project, University of Manchester, Manchester, UK. Available HTTP: $<\underline{\text { http://www.sed.manchester.ac.uk/architecture/research/ecocities/library/documents/G }}$ MLCLIP.pdf> (accessed 29th November 2010).

Merz, B., Thieken, A. H. and Gocht, M. (2007) Flood Risk Mapping At The Local Scale: Concepts and Challenges. In Begum, S., Stive, M. J. F. and Hall, J. W. (Eds.) Flood Risk Management in Europe, Springer: Dordrecht, The Netherlands.

National Audit Office (2001) Inland Flood Defence, London: The Stationery Office.

Parker, D. J. (1995) Floodplain Development Policy in England and Wales, Applied Geography, 15 (4): 341-363.

Pall, P., Aina, T., Stone, D. A., Stott, P. A., Nozawa, T., Hilberts, A. G. J., Lohmann, D. and Allen, M. $R$ (2011) Anthropogenic greenhouse gas contribution to flood risk in England and Wales in autumn 2000, Nature, (470), 382-385.

Perrow, C. (2007) The Next Catastrophe: Reducing our vulnerabilities to natural, industrial and terrorist disasters, Princeton: Princeton University Press.

Pitt, M. (2008) Learning Lessons from the 2007 Floods, an independent review by Sir Michael Pitt, London: Cabinet Office.

Reith, G. (2009) 'Uncertain Times: the notion of 'risk' and the development of modernity', in Lofstedt, R.E. and Boholm, A. (eds) The Earthscan Reader on Risk, London: Earthscan.

Scott Wilson and AGMA (2008) Strategic Flood Risk Assessment for Greater Manchester, Manchester: Scott Wilson.

White, I. (2010) Water and the City: Risk, Resilience and Planning for a Sustainable Future, Routledge: London.

White, I. and Howe, J. (2002) Flooding and the role of planning in England and Wales: A critical review, Journal of Environmental Planning and Management, 45 (5), 735-745.

White, I. and Richards, J. (2007) Planning Policy and Flood Risk: The Translation of National Guidance into Local Policy, Planning, Practice and Research, 22 (4), 513-514.

Wynne, B. (2009) 'Uncertainty and Environmental Learning: Reconceiving Science and Policy in the Preventative Paradigm', in Lofstedt, R.E. and Boholm, A. (eds) The Earthscan Reader on Risk, London: Earthscan.

Zevenbergen, C., Cashman, A., Evelpidou, N., Pasche, E., Garvin, S. and Ashley, R. (2010) Urban Flood Management, Taylor and Francis: Oxford. 